\title{
Long-term dietary fiber intake and risk of chronic obstructive pulmonary disease: a prospective cohort study of women
}

\author{
Maria Karolina Szmidt ${ }^{1}$ (D) . Joanna Kaluza ${ }^{1,2}$ (D) $\cdot$ Holly Ruth Harris $^{3,4} \cdot$ Anders Linden $^{5,6} \cdot$ Alicja Wolk $^{2,7}$ (D)
}

Received: 1 March 2019 / Accepted: 29 June 2019 / Published online: 6 July 2019

(c) The Author(s) 2019

\begin{abstract}
Purpose Until now, only two prospective cohort studies have investigated dietary fiber intake in relation to risk of chronic obstructive pulmonary disease (COPD), but neither examined long-term fiber intake. Both studies reported that total fiber intake was associated with decreased COPD risk; however, results for specific fiber sources were inconsistent. Thus, we prospectively evaluated the association between baseline and long-term intake of dietary fiber and COPD risk in a populationbased prospective cohort of 35,339 Swedish women.

Methods Dietary fiber intake was assessed in 1987 and 1997 with a food frequency questionnaire. Cox proportional hazard regression models were used to estimate hazard ratios (HRs) and 95\% confidence intervals (CIs).

Results During follow-up (2002-2014), 1557 COPD cases were identified via linkage to the Swedish National Patient Register. Long-term high dietary fiber intake ( $\geq 26.5$ vs. $<17.6 \mathrm{~g} /$ day) was associated with a $30 \%$ (95\% CI 17-41\%) lower risk of COPD. For specific fiber sources, cereal ( $\geq 16.3$ vs. $<9.4$ g/day; HR $0.67,95 \%$ CI $0.55-0.81)$ and fruit fiber $(\geq 7.6$ vs. $<2.6$ g/day; HR 0.65, 95\% CI 0.5-0.81), but not vegetable fiber intake ( $\geq 5.4$ vs. $<2.2$ g/day; HR 1.03, 95\% CI 0.81-1.28) were associated with lower COPD risk. Current and ex-smokers with low long-term total fiber intake ( $<17.6 \mathrm{~g} / \mathrm{day}) \mathrm{com}-$ pared to never smokers with high intake ( $\geq 26.5 \mathrm{~g} /$ day) had a 33-fold (95\% CI 23.6-46.6) and tenfold (95\% CI 7.0-16.3), respectively, higher risk of COPD.

Conclusions Our findings indicate that high fiber intake is a modifiable lifestyle factor which may decrease COPD risk primarily in current and ex-smokers.
\end{abstract}

Keywords Chronic obstructive pulmonary disease $\cdot$ Diet $\cdot$ Dietary fiber $\cdot$ Epidemiology $\cdot$ Prospective cohort study

\section{Introduction}

Electronic supplementary material The online version of this article (https://doi.org/10.1007/s00394-019-02038-w) contains supplementary material, which is available to authorized users.

Maria Karolina Szmidt

maria_szmidt@sggw.pl

1 Department of Human Nutrition, Warsaw University of Life Sciences-SGGW, 159C Nowoursynowska Str., 02-776 Warsaw, Poland

2 Unit of Cardiovascular and Nutritional Epidemiology, Institute of Environmental Medicine, Karolinska Institutet, 171-77 Stockholm, Sweden

3 Program in Epidemiology, Division of Public Health Sciences, Fred Hutchinson Cancer Research Center, Seattle, WA, USA
Globally, chronic obstructive pulmonary disease (COPD) is predicted by the World Health Organisation to become the third most common disease-related cause of mortality by the year 2030 [1]. Exposure to noxious particles or gases which

4 Department of Epidemiology, University of Washington, Seattle, WA, USA

5 Unit for Lung and Airway Research, Institute of Environmental Medicine, Karolinska Institutet, 171-77 Stockholm, Sweden

6 Department of Respiratory Medicine and Allergy, New Karolinska Solna, Karolinska University Hospital, 171-77 Stockholm, Sweden

7 Department of Surgical Sciences, Uppsala University, Uppsala, Sweden 
cause airway and/or alveolar abnormalities leads to COPD development; and tobacco smoking is COPD's main risk factor [1]. COPD is characterized by chronic inflammation which is usually initiated locally in the airways, but as the disease progresses, it becomes systemic [1,2]. It has been observed that, especially among smokers [3], chronically elevated serum concentrations of C-reactive protein (CRP) [4] and interleukin-6 (IL-6) [5] are associated with a loss of lung function and higher risk of COPD. Unfortunately, the efficacy of current pharmacotherapy against COPD remains poor; thus, it is important to seek modifiable lifestyle factors which could reduce risk of COPD. The health benefits of dietary fiber in relation to inflammatory diseases such as type 2 diabetes [6], metabolic syndrome [7] and cardiovascular diseases [8] have been well documented. Thus, it is feasible that dietary fiber intake, through anti-inflammatory [9-11] as well as indirect antioxidant properties [12], may protect lungs against inflammation and prevent COPD, especially through modulation of the innate immune system via the gut-liver-lung axis [13] and enhancing the bioavailability of antioxidants [14].

Until now, only two prospective cohort studies have investigated dietary fiber intake in relation to risk of COPD development. The first was conducted in two cohorts of US women and men [15] and the second in a cohort of Swedish men [16]. Results of these studies indicate that total as well as cereal dietary fiber are inversely associated with COPD incidence, while results obtained for fruit and vegetable fiber intake were inconsistent $[15,16]$. Fruit and vegetable fiber has been inversely associated with COPD incidence only among current smokers in the cohort of Swedish men [16]. Moreover, no previous studies have assessed the risk of COPD in relation to long term, in contrast to only baseline, dietary fiber intake.

In the current study, we hypothesized that intake of dietary fiber is a beneficial lifestyle choice that reduces the risk of COPD. To address this hypothesis, we investigated the associations between long-term total and specific fiber intake and incidence of COPD in the population-based prospective Swedish Mammography Cohort.

\section{Methods}

\section{Study population}

The Swedish Mammography Cohort (SMC) was established between 1987 and 1990 when all women living in Uppsala and Västmanland counties in central Sweden, and born during 1914-1948 $(n=90,303)$ were invited to a mammography screening and completed a food-frequency questionnaire. Among the 66,651 (response rate $=74 \%$ ) women who returned the questionnaire, we excluded those with missing or incorrect national identification number $(n=1988)$, history of cancer (other than non-melanoma skin cancer, $n=2437)$, and improbable total energy $( \pm 3$ SDs from the log-transformed mean energy intake, i.e., daily intake $<575 \mathrm{kcal}$ and $>4664 \mathrm{kcal}, n=793$ ) (Fig. 1). After these exclusions, the baseline prospective cohort consisted of 61,433 women. Ten years later, in 1997, a second expanded questionnaire was sent to all of the women who were still alive and were living in the same region of Sweden $(n=56,030)$. The completed questionnaires were received from 39,227 women (response rate $=70 \%$ ). From these women, we excluded those with missing or incorrect national identification number $(n=243)$, who were diagnosed with cancer $(n=1717)$ or COPD before 1998 (ICD-10 code: J44, $n=302$ ), and those with improbable total energy intake $(n=489)$. Additionally, due to a potential underdiagnosis in the first years of follow-up (1998-2001) and the necessity of a 4-year lag period introduction (details in the "Case ascertainment" section and in online Supplementary Material-Figure S1), women with COPD diagnosis between 1998 and $2001(n=160)$ or those who died during these 4 years $(n=977)$ were excluded as well. Thus, the final analytic cohort consisted of 35,339 women, aged $61.5 \pm 9.1$ years, who were comparable to the general Swedish female population in relation to age distribution, education, and BMI distribution [17]. In the present study, the data collected in 1997 were used as baseline because information on some important COPD risk factors, such as smoking and physical activity, was not obtained in 1987.

\section{Assessment of dietary fiber intake}

Data about food consumption were collected by food frequency questionnaires (FFQs) based on 67 food items in 1987 and 96 food items in 1997. Participants were asked about their average food consumption during the past year based on eight predefined frequency categories, ranging from "never/seldom" to "4 times per day" in 1987, and from "0 times per month" to " $3+$ times per day" in 1997. Dietary fiber intake was estimated by multiplying the frequency of intake of each food item by the fiber content (based on data from Swedish National Administration Database) [18] using age-specific portion sizes. Specific food items used in the calculation of dietary fiber intake are presented in Supplementary Table S1. Intake of cereal, fruit, and vegetable fiber was determined by summing the fiber components of individual food items that contributed to intake of each type of fiber. To minimize the effects of measurement error in dietary fiber intake, the residual method was used. Through this procedure "energy-adjusted" fiber intake was computed as the residual from the regression model using total caloric intake as the independent variable and absolute fiber intake as the dependent variable [19]. Using this method, fiber 
Fig. 1 Flow chart of the study population. (Superscript a) A 4-year lag period was introduced due to COPD under-diagnosis between 1998 and 2001 (details in online Supplementary Material and Supplementary Table S2)

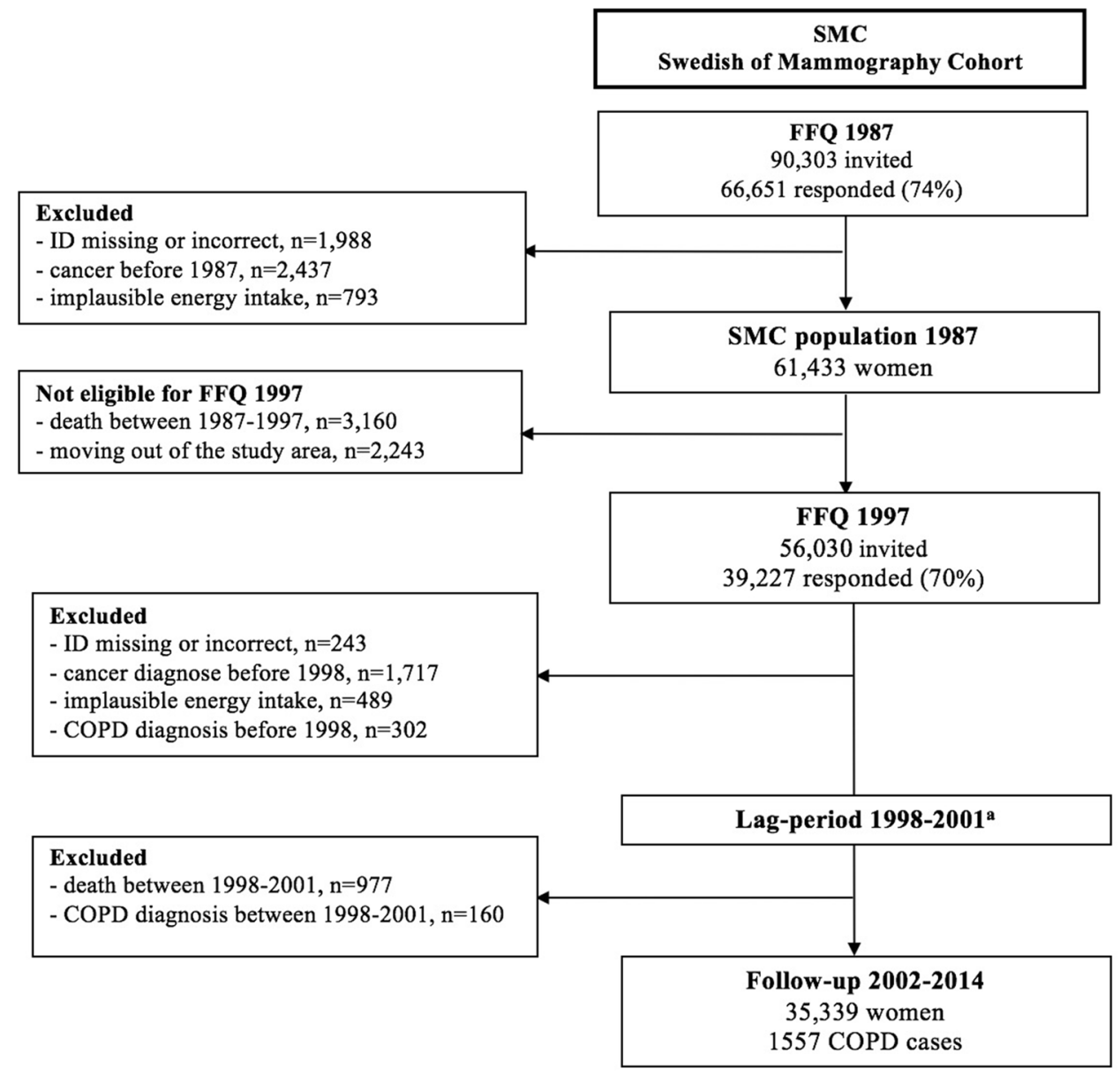

intake was adjusted for total energy intake to $1600 \mathrm{kcal} /$ day in 1987 and to $1700 \mathrm{kcal} /$ day in 1997 (the mean energy intake in both diet measurements) [20]. To calculate longterm dietary fiber intake, the cumulative average method was used based on data collected in 1987 (10 years prior baseline) and 1997 (baseline). This approach represents the most stable estimate of fiber intake and better represent the long-term dietary intake [21]. The 1997 FFQ has been validated among 248 study participants (aged 40-74 years old) in central Sweden, by comparing with fourteen 24-h recall interviews [22]. The Spearman correlation coefficient between the two methods for dietary fiber was 0.71 .

\section{Assessment of other exposures}

In the present study, information on covariates collected on the 1997 questionnaire was used as baseline. Women were asked about education level, weight, height, time per day spent on walking and/or cycling, smoking status, and alcohol consumption. Body Mass Index (BMI) was calculated by dividing the weight in kilograms by the square of the height in meters. Participants reported average number of cigarettes smoked per day at different ages (15-20, 21-30,
31-40, 41-50, 51-60 years old, and in the year of data collection), and indicated when they started and stopped smoking (only if this event occurred). Pack-years of smoking were calculated by multiplying the number of cigarettes smoked per day by number of years smoked, respectively, for each age category.

\section{Case ascertainment}

Linkage to the Swedish National Patient Registers (inpatient and outpatient) and the Swedish Cause of Death Register was performed using the unique personal identification number assigned to each Swedish resident. COPD diagnoses were identified in accordance with the International Classification of Diseases and Related Health Problems, 10th Revision (ICD-10 code: J44). Incident COPD cases were defined as the first diagnosis of COPD in the Swedish Patient Register (listed either as the primary or any diagnosis position) or in the Cause of Death Register (only the primary position). Taking into account that both medical registers in Sweden and several guidelines for the diagnosis and management of the COPD were created in the early $90 \mathrm{~s}$, there was a potential of under-diagnosis in the cohort [23, 24]. 
Furthermore, the results of a previous study reported that the proportion of COPD diagnoses increased from 59\% in 1999 to $81 \%$ in 2009 in Sweden [23]. Thus, due to potential under-diagnosis of COPD in the study cohort, we analyzed the annual occurrence of COPD cases in 1998 and 2014 (see online Supplementary Figure S1). This analysis indicated that during the first 4 years of follow-up (1998-2001), the number of COPD cases was lower than after 2001 (40 vs. 119 COPD cases per year); thus, we implemented a 4-year lag period and started analyses from 2002.

\section{Statistical analysis}

Women were followed from 1 January 2002 to 31 December 2014, and until COPD diagnosis, death, or the end of follow-up, whichever occurred first. Hazard ratios (HRs) and $95 \%$ confidence intervals (CIs) of COPD incidence were estimated using Cox proportional hazard regression models. Participants were assigned to quintiles of baseline energy-adjusted total dietary fiber intake $(<17.6,17.6-20.5$, 20.6-23.1, 23.2-26.4, and $\geq 26.5 \mathrm{~g} /$ day), and the same cutpoints were used for long-term fiber intake. For specific fiber intake (both baseline and long term), participants were assigned to quintiles of energy-adjusted consumption. For all dietary fiber exposures, the lowest quintile served as the reference group. Multivariable models were adjusted for: age (years, continuous), education (less than high school, high school, university), BMI ( $<18.5,18.5-24.9,25.0-29.9$, $\geq 30 \mathrm{~kg} / \mathrm{m}^{2}$ ), walking/cycling ( $<20,20-60,>60 \mathrm{~min} /$ day $)$, smoking status and pack-years of smoking (never; past $<20,20-39, \geq 40$ pack-years; current $<20,20-39, \geq 40$ pack-years), energy intake (kcal/day, quintiles), and alcohol intake (g/day, quintiles). For specific fiber sources, intakes of fiber from cereals, fruits, and vegetables were mutually adjusted by inclusion in the same multivariable model. Missing data on smoking status (1.8\%), educational level (0.3\%), BMI (1.7\%), and walking/cycling (7.8\%) were included as separate categories. Moreover, we investigated the combined effect of long-term total dietary fiber intake with smoking status (current, ex-, never smokers) where never-smoking women with the highest fiber intake were considered as the reference group.

To provide greater diagnostic power than unscaled residuals, the proportional hazards assumption was evaluated by regressing scaled Schoenfeld residuals against survival time, and evidence of rejection of the assumption was not found. To test linear trends, we used fiber intake as continuous variable. A likelihood ratio test was used to examine the interaction between long-term fiber intake and smoking status (ever vs. ex-smokers vs. current smokers) on COPD risk. The shape of the association between risk of COPD and long-term total dietary fiber intake was investigated using restricted cubic-splines with three knots (at the 10th, 50th, 90th percentile) [25]. This method allows the examination of the effect of a continuous predictor (long-term total dietary fiber intake) on an outcome (COPD incident) reducing model misspecification and providing insight into the relationship between long-term fiber intake and COPD. Statistical analyses were conducted using SAS v. 9.4. (SAS Institute Inc, Cary, NC, USA) and STATA v. 13 (StataCorp, College Station, TX, USA). All $P$ values were two-sided and values $\leq 0.05$ were considered statistically significant.

\section{Results}

\section{Characteristics of the cohort}

In 1997, the energy-adjusted mean total dietary fiber intake was $22.2 \pm 5.5$ (median 21.8) g/day and the contribution of cereal, fruit and vegetables to total fiber intake was $59.1 \%$, $23.2 \%, 17.5 \%$, respectively. The Spearman correlation coefficients between total fiber intake and cereal, fruit, and vegetable fiber were $0.57,0.53$, and 0.51 , respectively. Compared to women in the lowest quintile of total dietary fiber intake $(<17.6 \mathrm{~g} /$ day $)$, those in the highest quintile ( $\geq 26.4 \mathrm{~g} /$ day $)$ were less likely to be ever smokers and more likely to walk and/or cycle more than $20 \mathrm{~min} /$ day (Table 1). Women with the highest intake of dietary fiber compared to those with the lowest intake had, on average, more than twofold higher consumption of whole-grain products, fruits, and vegetables, while consuming less processed red meat and alcohol. In 1987, the energy-adjusted mean total dietary fiber intake was $24.4 \pm 5.5$ (median 24.1) g/day. Data on intake of dietary fiber collected using the 1987 FFQ and 1997 FFQ were characterized by high agreement (illustrated with the Bland-Altman plot in online Supplementary Figure S2).

\section{Baseline fiber intake}

During a mean follow-up of 11.5 years $(407,067$ personyears, 2002-2014), 1557 incident cases of COPD were identified. An inverse association between total baseline dietary fiber intake and risk of COPD development was observed (Table 2). Women in the highest quintile of total dietary fiber intake ( $\geq 26.5 \mathrm{~g} /$ day) compared to those in the lowest quintile ( $<17.6 \mathrm{~g} /$ day) had a $22 \%(95 \%$ CI 9-33\%) lower risk of COPD. Each 1-g increment in total fiber intake (up to $25 \mathrm{~g} /$ day) was associated with $3 \%$ (95\% CI 2-5\%) risk reduction of COPD. For specific fiber sources, we observed that cereal fiber and fruit fiber intake were inversely associated with risk of COPD (Table 2). The HRs between women in the highest and lowest quintiles of cereal fiber and fruit fiber were 0.84 (95\% CI 0.72-0.98) and 0.77 (95\% CI 0.65-0.91), 
Table 1 Age-standardized characteristics of 35,339 women in the Swedish Mammography Cohort (SMC) by quintiles of energy-adjusted total dietary fiber intake at baseline (1997)

\begin{tabular}{|c|c|c|c|c|c|c|}
\hline & \multicolumn{5}{|c|}{ Quintiles of dietary fiber intake, g/day (median) ${ }^{\mathrm{a}}$} & \multirow[t]{2}{*}{$P$ value } \\
\hline & $<17.6(15.6)$ & $17.6-20.5(19.2)$ & $20.6-23.1(21.8)$ & $23.2-26.4(24.6)$ & $\geq 26.5(29.1)$ & \\
\hline$N$ & 7016 & 7073 & 7072 & 7091 & 7087 & \\
\hline Age, years & $60.6 \pm 9.4^{\mathrm{c}}$ & $61.1 \pm 9.1$ & $61.8 \pm 9.1$ & $62.0 \pm 9.0$ & $62.0 \pm 9.0$ & $<0.001$ \\
\hline Fiber intake in $1987, \mathrm{~g} /$ day $^{\mathrm{d}}$ & $21.0(6.6)^{\mathrm{e}}$ & $23.0(6.1)$ & $24.2(6.1)$ & $25.5(6.4)$ & $27.0(7.1)$ & $<0.001$ \\
\hline Education, university, \% & 17.6 & 19.2 & 19.3 & 19.6 & 19.0 & 0.01 \\
\hline Body Mass Index, kg/m² & $24.9 \pm 4.0$ & $25.0 \pm 3.9$ & $25.0 \pm 3.9$ & $25.1 \pm 3.9$ & $25.2 \pm 4.0$ & $<0.001$ \\
\hline \multicolumn{7}{|l|}{ Walking/cycling, \% } \\
\hline $\begin{array}{l}<20 \mathrm{~min} / \text { day } \\
20-60 \mathrm{~min} / \text { day } \\
>60 \mathrm{~min} / \text { day }\end{array}$ & $\begin{array}{l}33.8 \\
44.0 \\
13.3\end{array}$ & $\begin{array}{l}28.6 \\
49.9 \\
14.1\end{array}$ & $\begin{array}{l}26.7 \\
50.1 \\
15.9\end{array}$ & $\begin{array}{l}24.8 \\
51.6 \\
16.7\end{array}$ & $\begin{array}{l}21.7 \\
50.7 \\
19.4\end{array}$ & 0.12 \\
\hline \multicolumn{7}{|l|}{ Smoking status, $\%$} \\
\hline $\begin{array}{l}\text { Current smokers } \\
\text { Ex-smokers } \\
\text { Never smokers }\end{array}$ & $\begin{array}{l}30.3 \\
21.1 \\
46.6\end{array}$ & $\begin{array}{l}23.6 \\
22.3 \\
52.5\end{array}$ & $\begin{array}{l}21.1 \\
23.0 \\
54.2\end{array}$ & $\begin{array}{l}18.8 \\
23.0 \\
56.5\end{array}$ & $\begin{array}{l}18.7 \\
24.3 \\
55.1\end{array}$ & 0.84 \\
\hline Alcohol consumption, g/day & $5.3 \pm 7.0$ & $4.6 \pm 5.4$ & $4.2 \pm 4.9$ & $3.7 \pm 4.2$ & $3.1 \pm 3.9$ & $<0.001$ \\
\hline Energy intake, kcal/day & $1750 \pm 564$ & $1752 \pm 522$ & $1737 \pm 501$ & $1727 \pm 498$ & $1725 \pm 539$ & $<0.001$ \\
\hline Whole-grain products, g/day & $61.0 \pm 60.0$ & $82.6 \pm 68.8$ & $96.5 \pm 73.8$ & $111 \pm 84.5$ & $127 \pm 88.0$ & $<0.001$ \\
\hline Fruits, g/day & $107 \pm 74$ & $150 \pm 89$ & $181 \pm 104$ & $217 \pm 122$ & $291 \pm 181$ & $<0.001$ \\
\hline Vegetables, g/day & $125 \pm 72$ & $159 \pm 82$ & $186 \pm 95$ & $214 \pm 107$ & $289 \pm 186$ & $<0.001$ \\
\hline Processed red meat, g/day & $31.8 \pm 29.2$ & $31.1 \pm 23.9$ & $30.8 \pm 25.5$ & $29.0 \pm 24.3$ & $25.1 \pm 24.0$ & $<0.001$ \\
\hline
\end{tabular}

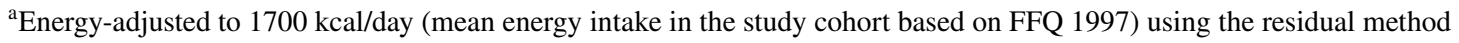

${ }^{\mathrm{b}} P$ values were calculated across quintiles of dietary fiber intake by using age-adjusted linear models for continuous variable and Pearson's Chi square for categorized variables

${ }^{\mathrm{c}}$ Mean $\pm \mathrm{SD}$-all such values

${ }^{\mathrm{d}}$ Energy-adjusted to $1600 \mathrm{kcal} /$ day (mean energy intake in the study cohort based on FFQ 1987) using the residual method

${ }^{\mathrm{e}}$ Median (interquartile range)

respectively. No association was observed for vegetable fiber intake and risk of COPD.

Due to the observed under-diagnosis of COPD incidence from 1998-2001, we performed a sensitivity analysis and calculated HRs stratified by time of diagnosis (see online Supplementary Table S2). The HRs in years 2002-2008 and 2009-2014 were consistent; between extreme quintiles of total fiber intake ( $\geq 26.5$ vs. $<17.6 \mathrm{~g} /$ day) were $0.75(95 \%$ CI $0.60-0.94)$ in 2002-2008 and 0.81 (95\% CI 0.65-1.00) in 2009-2014. In 1998-2001, a statistically significant association between dietary fiber intake and COPD risk was not observed (HR 1.02, 95\% CI 0.64-1.63). Taking into account the lower number of identified COPD cases in 1998-2001, we hypothesized that the lack of association was at least partly the result of under-diagnosis of COPD incidence during that period.

\section{Long-term fiber intake}

Taking into consideration long-term dietary fiber intake, reflecting the average intake at baseline (1997) and 10 years before baseline (1987), women in the highest vs. lowest quintiles of fiber intake had a 30\% (95\% CI 17-41\%) lower risk of COPD (Table 3). Using a restricted cubic spline analysis, we assessed the shape of the association between risk of COPD and long-term total dietary fiber intake, and observed a non-linear association, $P$ value for non-linearity $=0.005$ (Fig. 2). The risk of COPD decreased with increasing total dietary fiber intake up to $25 \mathrm{~g} /$ day, with each $1 \mathrm{~g} /$ day increment associated with 5\% (95\% CI 3-7\%) risk reduction, without a further decrease in risk with increasing intake.

Due to the potential importance of a woman's height in airflow from the lungs, we performed a sensitivity analysis replacing the BMI categories with quintiles of height and weight in the model. The results did not differ with a HR of 0.70 (95\% CI 0.59-0.82) comparing women in the highest vs. the lowest total dietary fiber intake.

For specific fiber sources, we observed an inverse association between risk of COPD and long-term cereal and fruit fiber intake (Table 3). Women with the highest cereal fiber intake and fruit fiber intake, compared to those with the lowest intake, had a 33\% (95\% CI 19-45\%) and 35\% (95\% CI $19-48 \%$ ) lower risk of COPD, respectively. No association 
Table 2 Hazard ratios (95\% CIs) of chronic obstructive pulmonary disease by quintiles of energy-adjusted baseline dietary fiber intake (1997) in 35,339 Swedish women, follow-up 2002-2014

\begin{tabular}{|c|c|c|c|c|c|c|c|}
\hline & \multicolumn{5}{|c|}{ Quintiles of dietary fiber intake, g/day (median) ${ }^{\mathrm{a}}$} & \multicolumn{2}{|c|}{$\begin{array}{l}\text { Dietary fiber intake up to } \\
25 \mathrm{~g} / \text { day }^{\mathrm{a}}\end{array}$} \\
\hline & & & & & & Per 1-g & $P$ trend \\
\hline Total fiber intake & $<17.6(15.6)$ & $17.6-20.5(19.2)$ & $20.6-23.1(21.8)$ & $23.2-26.4(24.6)$ & $\geq 26.5(29.1)$ & & \\
\hline No. of cases/no. women & $446 / 7016$ & $314 / 7073$ & $290 / 7072$ & 248/7091 & $259 / 7087$ & & \\
\hline $\begin{array}{l}\text { Age-adjusted HR (95\% } \\
\text { CI) }\end{array}$ & 1.00 & $0.67(0.58-0.77)$ & $0.61(0.53-0.71)$ & $0.51(0.44-0.59)$ & $0.53(0.46-0.62)$ & $0.92(0.91-0.94)$ & $<0.001$ \\
\hline $\begin{array}{l}\text { Age and smoke-adjusted } \\
\text { HR }(95 \% \mathrm{CI})\end{array}$ & 1.00 & $0.81(0.70-0.94)$ & $0.80(0.69-0.93)$ & $0.72(0.61-0.84)$ & $0.77(0.66-0.90)$ & $0.96(0.95-0.97)$ & $<0.001$ \\
\hline $\begin{array}{l}\text { Multivariable-adjusted } \\
\text { HR }(95 \% \mathrm{CI})^{\mathrm{b}}\end{array}$ & 1.00 & $0.84(0.73-0.98)$ & $0.83(0.72-0.97)$ & $0.74(0.63-0.87)$ & $0.78(0.67-0.91)$ & $0.97(0.95-0.98)$ & $<0.001$ \\
\hline Cereal fiber & $<9.4(7.9)$ & $9.4-11.6(10.6)$ & $11.7-13.5(12.5)$ & $13.6-16.2(14.7)$ & $\geq 16.3(18.6)$ & & \\
\hline No. of cases/no. women & $372 / 7261$ & $306 / 7261$ & $268 / 7261$ & $282 / 7261$ & $329 / 7261$ & & \\
\hline $\begin{array}{l}\text { Multivariable-adjusted } \\
\text { HR }(95 \% \mathrm{CI})^{\mathrm{b}}\end{array}$ & 1.00 & $0.89(0.76-1.03)$ & $0.80(0.68-0.93)$ & $0.83(0.71-0.97)$ & $0.84(0.72-0.98)$ & $0.98(0.96-1.00)$ & 0.01 \\
\hline Fruit fiber & $<2.6(1.8)$ & $2.6-4.0(3.2)$ & $4.1-5.3(4.6)$ & $5.4-7.5(6.3)$ & $\geq 7.6(9.4)$ & & \\
\hline No. of cases/no. women & $497 / 7244$ & $369 / 7278$ & $242 / 7261$ & $221 / 7261$ & $228 / 7261$ & & \\
\hline $\begin{array}{l}\text { Multivariable-adjusted } \\
\text { HR }(95 \% \mathrm{CI})^{\mathrm{b}}\end{array}$ & 1.00 & $1.00(0.87-1.14)$ & $0.78(0.66-0.90)$ & $0.73(0.61-0.86)$ & $0.77(0.65-0.91)$ & $0.95(0.92-0.97)$ & $<0.001$ \\
\hline Vegetable fiber & $<2.2(1.6)$ & $2.2-3.0(2.6)$ & $3.1-3.9(3.5)$ & $4.0-5.3(4.5)$ & $\geq 5.4(6.7)$ & & \\
\hline No. of cases/no. women & $411 / 7261$ & $317 / 7261$ & $282 / 7261$ & $243 / 7261$ & $304 / 7261$ & & \\
\hline $\begin{array}{l}\text { Multivariable-adjusted } \\
\text { HR }(95 \% \mathrm{CI})^{\mathrm{b}}\end{array}$ & 1.00 & $0.92(0.79-1.07)$ & $0.90(0.77-1.05)$ & $0.81(0.69-0.96)$ & $0.97(0.83-1.13)$ & $0.97(0.94-1.01)$ & 0.08 \\
\hline
\end{tabular}

$H R$ hazard ratio, $C I$ confidence interval

${ }^{a}$ Energy-adjusted to $1700 \mathrm{kcal} /$ day (mean energy intake in the study cohort based on FFQ 1997) using the residual method

${ }^{\mathrm{b}}$ Adjusted for age (continuous), education (less than high school, high school, or university), BMI ( $<18.5 ; 18.5-24.9 ; 25.0-29.9$, or $\geq 30.0 \mathrm{~kg} /$ $\left.\mathrm{m}^{2}\right)$, walking or cycling $(<20,20-60,>60 \mathrm{~min} /$ day), smoking status and pack-years of smoking (never; past $<20,20-39$, or $\geq 40$ pack-years; or current $<20,20-39$, or $\geq 40$ pack-years), intake of energy (kcal/day, quintiles) and alcohol consumption (g/day, quintiles)

was observed for vegetable fiber intake (Q5 vs. Q1, HR 1.03, 95\% CI 0.81-1.28).

\section{Findings by smoking status}

As smoking is the main risk factor for developing COPD, we conducted stratified analysis by smoking status (Table 4). Current and ex-smokers in the highest vs. lowest quintile of long-term fiber intake had a 26\% (95\% CI 9-40\%) and $36 \%$ (95\% CI 7-56\%) lower risk of COPD, respectively. A similar suggestion also was observed in never smokers, with HR 0.66 (95\% CI 0.37-1.19). In the dose-response analysis, each 1 -g increment in long-term dietary fiber intake up to $25 \mathrm{~g} /$ day was associated with 5\% (95\% CI 2-7\%) decreased risk in current smokers, 7\% (95\% CI 3-11\%) in ex-smokers, and 3\% in never smokers ( $95 \% \mathrm{CI}-4$ to $9 \%$ ). However, no statistically significant interaction was observed between long-term dietary fiber intake and smoking status (current vs. ex-smokers vs. never smokers $P$ interaction $=0.79$ ).

To investigate the combined effect of long-term dietary fiber intake and smoking status on risk of COPD, a comprehensive analysis which included current, ex-smokers and never smokers in one model was performed (Fig. 3). In comparison to never smokers in the highest quintile of fiber intake ( $\geq 26.5 \mathrm{~g} /$ day), current and ex-smokers with the lowest intake $(<17.6 \mathrm{~g}$ /day) had a 33 -fold (HR 33.2, 95\% CI 23.6-46.6) and 11-fold (HR 10.7, 95\% CI 7.0-16.3) higher risk of COPD, respectively. With increasing longterm dietary fiber intake, risk of COPD was decreased to 20-fold (HR 19.7, 95\% CI 14.1-27.5) for current smokers and sixfold (HR 6.4, 95\% CI 4.4-9.3) for ex-smokers.

\section{Discussion}

In this prospective cohort study of women, we found that high dietary fiber intake was inversely associated with the risk of COPD, and the risk was decreased in all categories of smoking status-current and ex-smokers, as well as never smokers. For specific fiber sources, cereal and fruit fiber, but not vegetable fiber, was inversely associated with COPD incidence. 
Table 3 Hazard ratios (95\% CIs) of chronic obstructive pulmonary disease by energy-adjusted long-term dietary fiber intake (data from 1987 to 1997) in 35,339 Swedish women, follow-up 2002-2014

Long-term dietary fiber intake, g/day (median) ${ }^{\mathrm{a}}$

\begin{tabular}{l} 
Long-term dietary fiber \\
intake up to $25 \mathrm{~g} /$ day $^{\mathrm{a}}$ \\
\hline Per 1-g $\quad P$ trend
\end{tabular}

\begin{tabular}{|c|c|c|c|c|c|c|c|}
\hline Total fiber & $<17.6(16.1)$ & $17.6-20.5(19.3)$ & $20.6-23.1(21.8)$ & $23.2-26.4(24.6)$ & $\geq 26.5(28.6)$ & & \\
\hline No. of cases/no. women & $267 / 3528$ & $307 / 6149$ & $363 / 8014$ & $307 / 9384$ & $313 / 8264$ & & \\
\hline $\begin{array}{l}\text { Age-adjusted HR (95\% } \\
\text { CI) }\end{array}$ & 1.00 & $0.62(0.52-0.73)$ & $0.54(0.46-0.63)$ & $0.37(0.32-0.44)$ & $0.43(0.36-0.50)$ & $0.89(0.88-0.91)$ & $<0.001$ \\
\hline $\begin{array}{l}\text { Age and smoke-adjusted } \\
\text { HR }(95 \% \text { CI })\end{array}$ & 1.00 & $0.77(0.65-0.90)$ & $0.77(0.65-0.90)$ & $0.57(0.48-0.67)$ & $0.69(0.58-0.81)$ & $0.94(0.93-0.96)$ & $<0.001$ \\
\hline $\begin{array}{l}\text { Multivariable-adjusted } \\
\text { HR }(95 \% \mathrm{CI})^{\mathrm{b}}\end{array}$ & 1.00 & $0.80(0.67-0.94)$ & $0.81(0.69-0.95)$ & $0.60(0.51-0.71)$ & $0.70(0.59-0.83)$ & $0.95(0.93-0.97)$ & $<0.001$ \\
\hline Cereal fiber & $<9.4(8.4)$ & $9.4-11.6(10.7)$ & $11.7-13.5(12.6)$ & $13.6-16.2(14.8)$ & $\geq 16.3(18.3)$ & & \\
\hline $\begin{array}{l}\text { No. of cases/no. of } \\
\text { women }\end{array}$ & $136 / 2021$ & $237 / 4781$ & $292 / 7120$ & $409 / 10,294$ & $483 / 11,123$ & & \\
\hline $\begin{array}{l}\text { Multivariable-adjusted } \\
\text { HR }(95 \% \text { CI })^{\mathrm{b}}\end{array}$ & 1.00 & $0.80(0.64-0.99)$ & $0.72(0.59-0.89)$ & $0.69(0.56-0.84)$ & $0.67(0.55-0.81)$ & $0.96(0.94-0.98)$ & $<0.001$ \\
\hline Fruit fiber & $<2.6(1.9)$ & $2.6-4.0(3.3)$ & $4.1-5.3(4.6)$ & $5.4-7.5(6.2)$ & $\geq 7.6(10.0)$ & & \\
\hline $\begin{array}{l}\text { No. of cases/no. of } \\
\text { women }\end{array}$ & $591 / 8185$ & $410 / 9148$ & $259 / 8204$ & $198 / 6414$ & $99 / 3388$ & & \\
\hline $\begin{array}{l}\text { Multivariable-adjusted } \\
\text { HR }(95 \% \text { CI })^{\mathrm{b}}\end{array}$ & 1.00 & $0.88(0.77-1.00)$ & $0.70(0.60-0.81)$ & $0.68(0.57-0.80)$ & $0.65(0.52-0.81)$ & $0.90(0.87-0.94)$ & $<0.001$ \\
\hline Vegetable fiber & $<2.2(1.6)$ & $2.2-3.0(2.6)$ & $3.1-3.9(3.4)$ & $4.0-5.3(4.4)$ & $\geq 5.4(6.2)$ & & \\
\hline $\begin{array}{l}\text { No. of cases/no. of } \\
\text { women }\end{array}$ & $679 / 13,492$ & $378 / 9686$ & $243 / 6339$ & $171 / 3856$ & $86 / 1966$ & & \\
\hline $\begin{array}{l}\text { Multivariable-adjusted } \\
\text { HR }(95 \% \mathrm{CI})^{\mathrm{b}}\end{array}$ & 1.00 & $0.98(0.86-1.12)$ & $1.04(0.90-1.22)$ & $1.16(0.97-1.38)$ & $1.03(0.81-1.28)$ & $0.96(0.91-1.01)$ & 0.14 \\
\hline
\end{tabular}

$H R$ hazard ratio, $C I$ confidence interval

${ }^{a}$ Long-term consumption was calculated as a cumulative average of energy-adjusted dietary fiber intake from 1987 to 1997

${ }^{\mathrm{b}}$ Adjusted for age (continuous), education (less than high school, high school, or university), BMI ( $<18.5 ; 18.5-24.9 ; 25.0-29.9$, or $\geq 30.0 \mathrm{~kg}$ / $\mathrm{m}^{2}$ ), walking or cycling $(<20,20-60,>60 \mathrm{~min} /$ day), smoking status and pack-years of smoking (never; past $<20,20-39$, or $\geq 40$ pack-years; or current $<20,20-39$, or $\geq 40$ pack-years), intake of energy (kcal/day, quintiles) and alcohol consumption (g/day, quintiles)

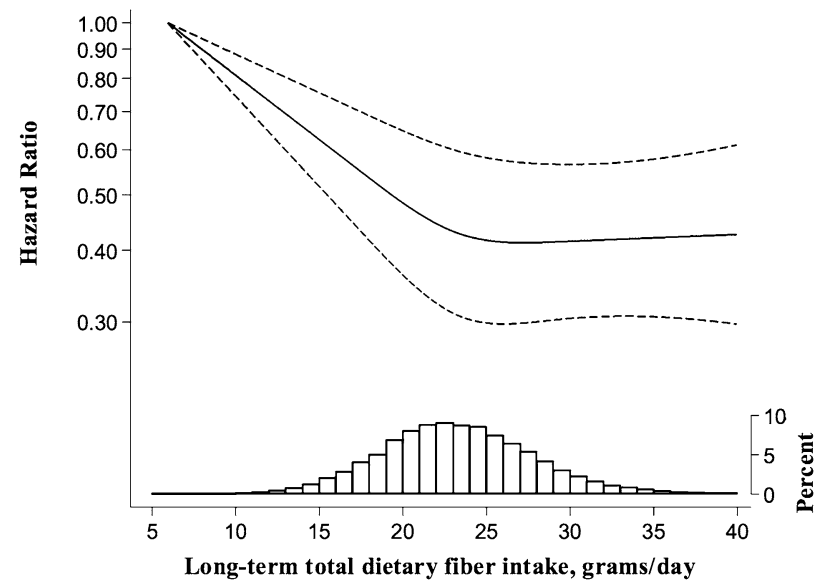

Fig. 2 Multivariable-adjusted hazard ratios (solid line) of COPD incidence as a function of long-term total dietary fiber intake among Swedish women $(P$ value for non-linearity $=0.005)$. The hazard ratio is presented on the log scale. The long-dashed lines represent $95 \%$ confidence intervals. The distribution of long-term total dietary fiber intake is presented at the bottom of the figure as a histogram
Our findings confirm and expand upon the results from two previous prospective cohort studies (US-based study including 40,215 men and 71,365 women, 832 COPD cases [15] and Swedish study including 45,058 men, 1982 COPD cases [16]) which indicated that total intake of dietary fiber was inversely associated with risk of COPD. Those studies observed that participants in the highest vs. the lowest quintile of dietary fiber intake had a 33\% (95\% CI 10-50\%, $P$ trend $=0.03$ ) [15] and 38\% (95\% CI 29-47\%, $P$ trend $<0.0001)$ [16] lower risk of COPD, respectively. Our findings are also in line with a previous cross-sectional study which investigated associations between total dietary fiber intake and lung function among 11,897 US participants [26], where higher fiber intake was associated with higher forced expiratory volume in $1 \mathrm{~s}\left(\mathrm{FEV}_{1}\right)$, forced vital capacity $(\mathrm{FVC})$ and $\mathrm{FEV}_{1} / \mathrm{FVC}$ ratio.

Moreover, some previous studies have examined the associations between dietary patterns and risk of COPD. A "Prudent" dietary pattern (rich in whole grains, fruits, 
Table 4 Hazard ratios (95\% CIs) of chronic obstructive pulmonary disease by energy-adjusted long-term total dietary fiber intake (data from 1987 to 1997) stratified by smoking status in Swedish women, follow-up 2002-2014

\begin{tabular}{|c|c|c|c|c|c|c|c|}
\hline & \multicolumn{5}{|c|}{ Long-term total dietary fiber intake, g/day (median) ${ }^{\mathrm{a}}$} & \multicolumn{2}{|c|}{$\begin{array}{l}\text { Long-term dietary fiber } \\
\text { intake up to } 25 \mathrm{~g} / \text { day }^{\mathrm{a}}\end{array}$} \\
\hline & $<17.6(16.1)$ & $17.6-20.5(19.3)$ & $20.6-23.1(21.8)$ & $23.2-26.4(24.6)$ & $\geq 26.5$ (28.6) & Per 1-g & $P$ trend \\
\hline \multicolumn{8}{|l|}{ Current smokers } \\
\hline $\begin{array}{l}\text { No. of cases/no. of } \\
\text { women }\end{array}$ & $203 / 1259$ & $221 / 1706$ & $235 / 1770$ & $174 / 1774$ & $187 / 1449$ & & \\
\hline $\begin{array}{l}\text { Multivariable-adjusted } \\
\text { HR }(95 \% \mathrm{CI})^{\mathrm{b}}\end{array}$ & 1.00 & $0.81(0.67-0.99)$ & $0.81(0.67-0.98)$ & $0.56(0.46-0.69)$ & $0.74(0.60-0.91)$ & $0.95(0.93-0.98)$ & $<0.001$ \\
\hline \multicolumn{8}{|l|}{ Ex-smokers } \\
\hline $\begin{array}{l}\text { No. of cases/no. of } \\
\text { women }\end{array}$ & $46 / 796$ & $55 / 1370$ & $78 / 1823$ & $73 / 2085$ & $78 / 1920$ & & \\
\hline $\begin{array}{l}\text { Multivariable-adjusted } \\
\text { HR }(95 \% \mathrm{CI})^{\mathrm{b}}\end{array}$ & 1.00 & $0.71(0.48-1.06)$ & $0.78(0.54-1.13)$ & $0.58(0.40-0.84)$ & $0.64(0.44-0.93)$ & $0.93(0.89-0.97)$ & $<0.001$ \\
\hline \multicolumn{8}{|l|}{ Never smokers } \\
\hline $\begin{array}{l}\text { No. of cases/no. of } \\
\text { women }\end{array}$ & $16 / 1412$ & $29 / 2957$ & $48 / 4295$ & $55 / 5356$ & $42 / 4731$ & & \\
\hline $\begin{array}{l}\text { Multivariable-adjusted } \\
\text { HR }(95 \% \text { CI })^{\mathrm{c}}\end{array}$ & 1.00 & $0.82(0.45-1.52)$ & $0.89(0.51-1.58)$ & $0.79(0.45-1.39)$ & $0.66(0.37-1.19)$ & $0.97(0.91-1.04)$ & 0.39 \\
\hline
\end{tabular}

$H R$ hazard ratio, $C I$ confidence interval

${ }^{a}$ Long-term consumption was calculated as a cumulative average of energy-adjusted dietary fiber intake from 1987 to 1997

${ }^{\mathrm{b}}$ Adjusted for age (continuous), education (less than high school, high school, or university), BMI ( $<18.5 ; 18.5-24.9 ; 25.0-29.9$, or $\geq 30.0 \mathrm{~kg}$ / $\left.\mathrm{m}^{2}\right)$, walking or cycling $(<20,20-60,>60 \mathrm{~min} /$ day), smoking status and pack-years of smoking (never; past $<20,20-39$, or $\geq 40$ pack-years; or current $<20,20-39$, or $\geq 40$ pack-years), intake of energy (kcal/day, quintiles) and alcohol consumption (g/day, quintiles)

${ }^{\mathrm{c}}$ Adjusted as above with exception pack-years of smoking

Fig. 3 Hazard ratios (95\% confidence intervals) of chronic obstructive pulmonary disease by long-term energyadjusted total dietary fiber intake and smoking status in Swedish women $(P$ value for interaction $=0.52$ ), follow-up 2002-2014

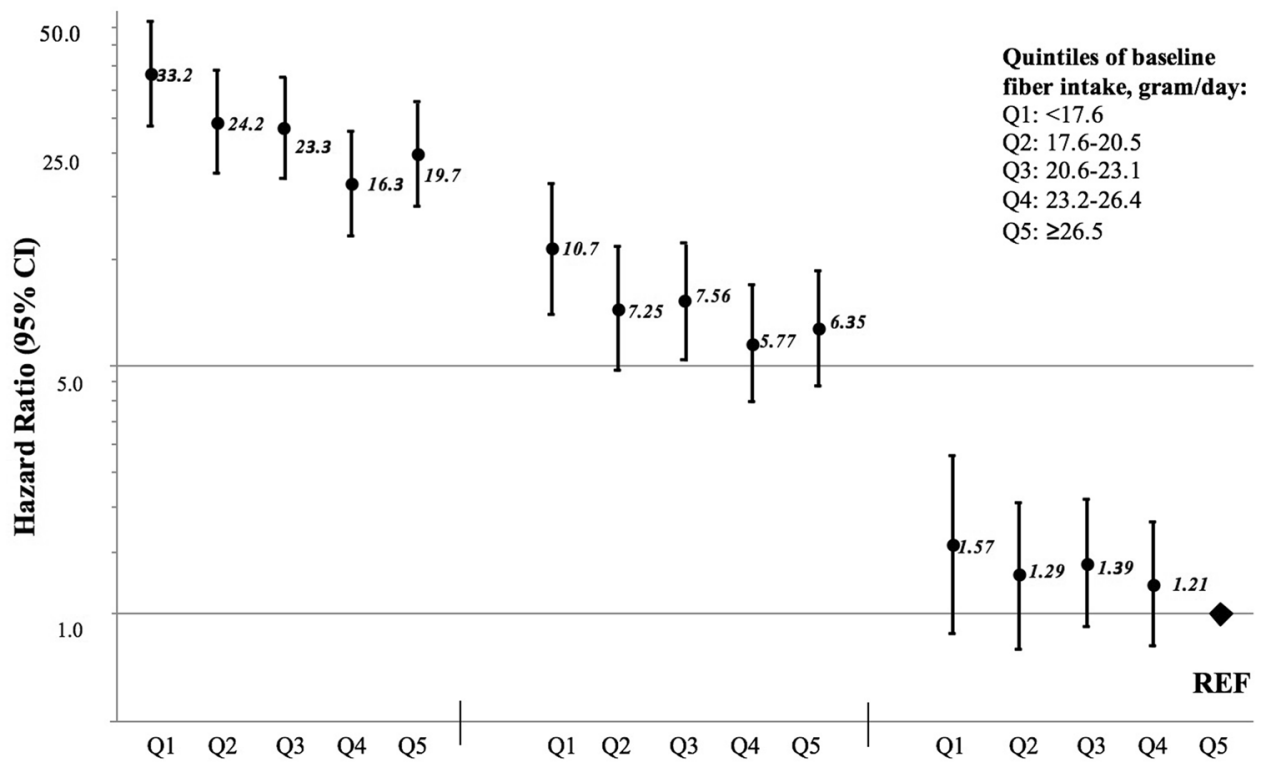

Current smokers
Ex-smokers
Never smokers vegetables, fish, poultry) which is characterized by high amounts of dietary fiber, was inversely associated with COPD risk [27-29]. Moreover, results of those studies showed that a "Western" dietary pattern (rich in refined grains, sugar, cured and red meat, French-fries), which contains low amounts of fiber, was positively associated with risk of COPD [27-29]. Furthermore, participants with the highest vs. the lowest degree of "Western" dietary 
pattern had lower $\mathrm{FEV}_{1}, \mathrm{FVC}$ and $\mathrm{FEV}_{1} / \mathrm{FVC}$ ratio, while those with the highest vs. the lowest "Prudent" dietary pattern had higher values of spirometry parameters [27]. Results of these studies indicate that the presence of healthy diet ("Prudent" dietary pattern) and absence of unhealthy diet ("Western" dietary pattern) may be associated with a lower risk of COPD.

Considering sources of dietary fiber intake, our results confirmed findings of previous studies that higher consumption of cereal fiber was associated with lower risk of COPD $[15,16]$. Among US participants, cereal fiber was inversely associated with lower risk of COPD, while similar associations were not observed for fruit and vegetable fiber [15]. Among Swedish men, cereal and fruit fiber was associated with lower risk in current and ex-smokers, while vegetable fiber was inversely associated only in current smokers [16]. The lack of an inverse association between vegetable fiber intake and COPD incidence could be explain by the higher uptake of heavy metals, especially cadmium and lead, in vegetables compared to fruits [30, 31]. Among smokers who are already exposed to toxic substances in the form of cigarette smoke, including heavy metals, each additional source of harmful substances (e.g., cadmium and lead in vegetables), could add to the adverse effects in the lung caused by smoking. Moreover, vegetables contain higher amounts of nitrate than fruits, and the source about $80 \%$ of this form of nitrogen in the usual diet is raw vegetables [32]. In 2008, the European Food Safety Authority stated that the conversion of nitrate into nitrite in vegetables (by salivary enzymes and oral bacteria or during storage) may contribute to adverse health effects [33]. Nitrate metabolites and their reaction products (e.g., peroxynitrite) provoke inflammatory processes in the airway and lung parenchyma, impairing respiratory homeostasis and causing cell damage [34].

In contrast to a previous study of Swedish men [16], we did not observe a significant interaction between dietary fiber intake and smoking status in relation to risk of COPD in Swedish women. However, the results for current and exsmokers in the current study are in line with those obtained for men [16]. The observed risk reduction for total dietary fiber intake was higher among men who were current smokers compared to women who were current smokers; while among ex-smokers, the results were quite similar for men and women [16]. The observed differences between current smoking between men and women may be due to the amounts of total dietary fiber intake and contribution of different fiber sources. Total dietary fiber intake was 1.5 -fold higher among men [16] than women (medians Q1-Q5 were $20.5-40.9 \mathrm{~g} / \mathrm{day}$ in men, and 16.1-28.6 g/day in women), and the contribution of cereal fiber to total fiber intake was $67 \%$ in men and $59 \%$ in women, fruit fiber was $12 \%$ in men and $23 \%$ in women, while vegetable fiber was $9 \%$ and $18 \%$, respectively. Moreover, differences between results obtained for Swedish women and men [16] could be related to differences in smoking intensity and smoking pack-years within these two cohorts. Median pack-years of smoking was higher among men (18.1 pack-years) compared to women (12.9 pack-years). Furthermore, women may have a different sensitivity to harmful components present in cigarette smoke, and it may be a result of sex-specific pathogenic mechanisms, sex hormones, or different baseline health status of men and women.

Various potential mechanisms involving a role of dietary fiber in the modulation of systemic tissue inflammation may explain the inverse association between dietary fiber intake and risk of COPD. Prior studies have demonstrated that higher dietary fiber intake decreased the concentration of pro-inflammatory mediators such as IL-6 and CRP [9-11]. Results from two US studies have showed that participants with the highest vs. the lowest total fiber intake had a $63 \%$ and 32\% lower risk of high concentrations of CRP and IL-6, respectively. It has also been reported that dietary fiber may lower risk of COPD through modulating the innate immune system via the gut-liver-lung axis [13]. This mechanism focuses on the impact of dietary fiber on the gut microbiome, which plays a key role in the function of the host immune system [35]. One of the products of bacterial fermentation of fiber in the gut is the short-chain fatty acids (SCFA), which have been linked to immune response [36, 37]. Acetate, propionate and butyrate, synthesized in the bowel by beneficial bacteria through fermentation of insoluble fiber (present in high amounts in whole grains, nuts, some vegetables) [37, 38], are absorbed into the circulation and then can be used by liver to modify innate immune response. SCFA can modify immune response to pulmonary inflammation [39] through the activation of G-protein receptors on neutrophils and macrophages, inhibiting histone deacetylase, 3-hydroxy-3-methylglutaryl-coenzyme A reductase and nuclear factor- $\mathrm{\kappa B}(\mathrm{NF}-\kappa \mathrm{B})$. These processes may result in decreased concentration of pro-inflammatory serum parameters such as IL-6 and CRP [40-42].

It seems feasible that dietary fiber may have a beneficial impact on reducing oxidative stress in the lungs via the antioxidant capacity of fruit and vegetables, thus, lowering the risk of COPD. Antioxidants such as polyphenols and carotenoids traverse the small intestine in conjunction with dietary fiber and may release the fiber matrix exclusively in the colon through the action of the microbiota [14]. Linkage to dietary fiber seems to be crucial for adequate assimilation of antioxidants in the gut $[12,14]$.

In light of the considerations above, dietary fiber seems to be a unique and important nutrient in the prevention of COPD, especially among smokers. Due to the modulation of the innate immune system via the gut-liver-lung axis and reduction in oxidative stress via enhancing bioaccessibility of antioxidants from fruits and vegetables, dietary fiber 
appears to be unique, even when compared to other nutrients with anti-inflammatory and anti-oxidative properties.

As strengths of this study, the following aspects should be considered: a large population-based prospective cohort and a large number of COPD cases which allowed sufficient power for comprehensive statistical analyses. This is the first study which examined long-term dietary fiber intake in relation to COPD incidence. Data on fiber intake had high validity [22]. Moreover, the available data on COPD risk factors allowed us to thoroughly adjust for potential confounders; however, some variables which are related to COPD development could not be included in the analysis (e.g. exposure to air pollution or occupational exposures). FFQ-based dietary data despite high validity could be misclassified between quintiles of total and specific sources of fiber intake. Furthermore, during the years of follow-up, diagnoses of COPD were based on post-bronchodilator values with a fixed FEV1/FVC ratio; however, some patients could have been classified as having COPD without the correct spirometry assessment, even though this investigation is formally required for a clinical diagnosis. Thus, the misdiagnosis of COPD could have been occurred for some participants resulting in under- or over-diagnosis. Indeed, in the first years of follow-up, the number of COPD events was under-diagnosed, and the observed results were attenuated; thus, we introduced the 4-year lag period to handle with this effect. Moreover, it is possible that using other criteria for COPD diagnosis could alter the results. In a recently published cross-sectional Danish study, low intake of fruits and raw vegetables was associated with an increased risk of COPD; the risk estimates were lower using the fixed FEV1/FVC ratio $<0.70$ plus respiratory symptoms diagnosis compared to those using the lower limit of normal (LLN) criteria to define a diagnosis COPD in spite of a higher number of defined COPD cases [43].

Our study strengthens and expands previous evidence that, in addition to smoking cessation, intake of dietary fiber as a modifiable lifestyle factor may reduce the risk of COPD for both ex- and current long-term smokers. Therefore, our results support the recommendation to increase consumption of products high in dietary fiber especially among smokers. Furthermore, these findings indicate the need to conduct intervention studies on the clinical utility of recommending intake of at least $25 \mathrm{~g}$ of fiber/day to reduce the risk of COPD among long-term smokers.

Authors contributions MS, JK had full access to all data in the study and takes responsibility for the integrity of the data analysis; MS, JK, AL and AW: study concept and design; MS and JK performed the statistical analysis; MS, JK, HRH: write the manuscript; HRH, AL and AW: critical revision of the manuscript for important intellectual content. All authors approved the final version of the manuscript.

Funding The study was supported by a research Grant from the Swedish Research Council/Infrastructure (AW) and the Karolinska Institutet's Distinguished Professor Award (AW).

\section{Compliance with ethical standards}

Conflict of interest The authors declare that they have no conflict of interest.

Ethical approval The study was approved by the Central Ethical Review Board in Stockholm, Sweden (decision no. 2016/2034-31/1), and response to the questionnaire was considered implied consent.

Open Access This article is distributed under the terms of the Creative Commons Attribution 4.0 International License (http://creativeco mmons.org/licenses/by/4.0/), which permits unrestricted use, distribution, and reproduction in any medium, provided you give appropriate credit to the original author(s) and the source, provide a link to the Creative Commons license, and indicate if changes were made.

\section{References}

1. Vogelmeier CF, Criner GJ, Martinez FJ et al (2018) Global strategy for the diagnosis, management, and prevention of chronic obstructive lung disease 2017 report: GOLD executive summary. Am J Respir Crit Care Med 195:557-582

2. Barnes PJ (2016) Inflammatory mechanisms in patients with chronic obstructive pulmonary disease. J Allergy Clin Immunol 138:16-27

3. Kuo SM (2013) The interplay between fiber and the intestinal microbiome in the inflammatory response. Adv Nutr 4:16-28

4. Dahl M, Vestbo J, Lange P, Bojesen SE, Tybjaerg-Hansen A, Nordestgaard BG (2007) C-reactive protein as a predictor of prognosis in chronic obstructive pulmonary disease. Am J Respir Crit Care Med 175:250-255

5. Wei J, Xiong XF, Lin YH, Zheng BX, Cheng DY (2015) Association between serum interleukin- 6 concentrations and chronic obstructive pulmonary disease: a systematic review and metaanalysis. PeerJ 3:e1199

6. Yao B, Fang H, Xu W, Yan Y, Xu H, Liu Y, Mo M, Zhang H, Zhao Y (2014) Dietary fiber intake and risk of type 2 diabetes: a dose-response analysis of prospective studies. Eur J Epidemiol 29:79-88

7. Wei B, Liu Y, Lin X, Fang Y, Cui J, Wan J (2018) Dietary fiber intake and risk of metabolic syndrome: a meta-analysis of observational studies. Clin Nutr 37:1935-1942

8. McRae MP (2017) Dietary fiber is beneficial for the prevention of cardiovascular disease: an umbrella review of meta-analyses. J Chiropr Med 16:289-299

9. Ma Y, Griffith JA, Chasan-Taber L, Lendzki BC, Jackson E, Stanek EJ, Li W, Pagoto SL, Hafner AR, Ockene IS (2006) Association between dietary fiber and serum C-reactive protein. Am J Clin Nutr 83:760-766 
10. Ma Y, Hébert JR, Li W et al (2008) Association between dietary fiber and markers of systemic inflammation in the Women's Health Initiative Observational Study. Nutr 24:941-949

11. King DE, Egan BM, Geesey ME (2003) Relation of dietary fat and fiber to elevation of C-reactive protein. Am J Cardiol 92:1335-1339

12. Saura-Calixto F (2011) Dietary fiber as a carrier of dietary antioxidants: an essential physiological function. J Agric Food Chem 59:43-49

13. Young RP, Hopkins RJ, Marsland B (2016) The gut-liver-lung axis. Modulation of the innate immune response and its possible role in chronic obstructive pulmonary disease. Am J Respir Cell Mol Biol 54:161-169

14. Palafox-Carlos H, Ayala-Zavala JF, González-Aguilar GA (2011) The role of dietary fiber in the bioaccessibility and bioavailability of fruit and vegetable antioxidants. J Food Sci 76:R6-R15

15. Varraso R, Willett WC, Camargo CA (2010) Prospective study of dietary fiber and risk of chronic obstructive pulmonary disease among US women and men. Am J Epidemiol 171:776-784

16. Kaluza J, Harris H, Wallin A, Linden A, Wolk A (2018) Dietary fiber intake and risk of chronic obstructive pulmonary disease: a prospective cohort study of men. Epidemiology 29:254-260

17. Harris H, Håkansson N, Olofsson C, Stackelber O, Julin Bm Åkesson A, Wolk A (2013) The Swedish mammography cohort and the cohort of Swedish men: study design and characteristics of two population-based longitudinal cohorts. OA Epidemiol 1:16-24

18. Bergström L, Kylberg E, Hagman U et al (1991) The food composition database KOST: the National Administration's information system for nutritive values of food. Vaar Föda 43:439-447

19. Willett W (2013) Implications of total energy intake for epidemiologic analyses. In: Willett W (ed) Nutritional epidemiology, 3rd edn. Oxford University Press, New York, pp 26-286

20. Willet WC, Howe GR, Kushi LH (1997) Adjustment for total energy intake in epidemiologic studies. Am J Clin Nutr 65(suppl):1220S-1228S

21. Hu FB, Stampfer MJ, Rimm E, Ascherio A, Rosner BA, Spiegelman D, Willett WC (1999) Dietary fat and coronary heart disease: a comparison of approaches for adjusting for total energy intake and modeling repeated dietary measurements. Am J Epidemiol 149:531-540

22. Messerer M, Johansson SE, Wolk A (2004) The validity of questionnaire-based micronutrient intake estimates is increased by including dietary supplement use in Swedish men. J Nutr 134:1800-1805

23. Ställberg B, Janson C, Johansson Larsson K, Stratelis G, Telg G, Lissper KH (2014) Management, morbidity and mortality of COPD during an 11-year period: an observational retrospective epidemiological register study in Sweden (PATHOS). Prim Care Respir J 23:38-45

24. Lindström M, Jönsson E, Larsson K, Lundbäck B (2002) Underdiagnosis of chronic obstructive pulmonary disease in Northern Sweden. Int J Tuberc Lung Dis 6:76-84

25. Harrell FE, Lee KL, Pollock BG (1988) Regression models in clinical studies: determining relationships between predictors and response. J Natl Cancer Inst 80:1198-1202

26. Kan H, Stevens J, Heiss G, Rose KM, London SJ (2008) Dietary fiber, lung function, and chronic obstructive pulmonary disease in the atherosclerosis risk in communities study. Am J Epidemiol 167:570-578

27. Brigham EP, Steffen LM, London SJ, Boyce D, Diette GB, Hansel NN, Rice J, McCormack MC (2018) Diet pattern and respiratory morbidity in the atherosclerosis risk in communities study. Ann Am Thorac Soc 15:675-682

28. Varraso R, Fung TT, Hu FB, Willet W, Camargo CA (2007) Prospective study of dietary patterns and chronic obstructive pulmonary disease among US men. Thorax 62:786-791

29. Varraso R, Fung TT, Barr RG, Hu FB, Willet W, Camargo CA (2008) Prospective study of dietary patterns and chronic obstructive pulmonary disease among US women. Am J Clin Nutr $86: 488-495$

30. Norton GJ, Deacon CM, Mestrot A, Feldmann J, Jenkins P, Baskaran C, Meharg AA (2015) Cadmium and lead in vegetable and fruit produce selected from specific regional areas of the UK. Sci Total Environ 533:520-527

31. Venugopal NVS, Narasimhulu K, Sainadh NVS (2014) Determination of trace amounts of cadmium in fruits, vegetables and cosmetic products by using atomic absorption spectrophotometry. Int J Chem Appl 6:103-107

32. Colla G, Kim H-J, Kyriacou MC, Rouphael Y (2018) Nitrate in fruits and vegetables. Sci Hortic 237:221-238

33. European Food Safety Authority (2008) Nitrate in vegetablesscientific opinion of the panel on contaminants in the food chain: nitrate in vegetables-scientific opinion of the panel on contaminants in the food chain. EFSA J 689:1-79

34. Ricciardolo FL, Di Stefano A, Sabatini F, Folkerts G (2006) Reactive nitrogen species in the respiratory tract. Eur J Pharmacol 533:240-252

35. Belkaid Y, Hand TW (2014) Role of the microbiota in immunity and inflammation. Cell 157:121-141

36. Kau AL, Ahern PP, Griffin NW, Goodman AL, Gordon JI (2011) Human nutrition, the gut microbiome, and immune system: envisioning the future. Nature 474:327-336

37. Meier RF (2009) Basics in clinical nutrition: fibre and short chain fatty acids. E Spen Eur E J Clin Nutr Metab 4:e69-e71

38. Roy CC, Kien CL, Bouthillier L, Levy E (2006) Short-chain fatty acids: ready for prime time? Nutr Clin Pract 21:351-366

39. Trompette A, Gollwitzer ES, Yadava K et al (2014) Gut microbiota metabolism of dietary fiber influences allergic airway disease and hematopoiesis. Nat Med 20:159-166

40. Marsland BJ (2012) Regulation of inflammatory responses by the commensal microbiota. Thorax 67:93-94

41. Maslowski KM, Vieira AT, Ng A et al (2009) Regulation of inflammatory responses by gut microbiota and chemoattractant receptor GPR43. Nature 46:1282-1286

42. Sun M, Wu W, Liu Z, Cong Y (2017) Microbiota metabolite short chain fatty acids, GPCR, and inflammatory bowel diseases. J Gastroenterol 52:1-8

43. Meteran H, Thomsen SF, Miller MR, Hjelmborg J, Sigsgaard T, Backer V (2018) Self-reported intake of fruit and vegetables and risk of chronic obstructive pulmonary disease: a nation-wide twin study. Respir Med 144:16-21 